\title{
Water-Saving Technologies for Coal-Fired Power Plant
}

\author{
N. HU, Y.F. PEI \\ Northeast Electric Power Design Institute Co., Ltd. of China Power Engineering Consulting Group, \\ Changchun, China
}

\begin{abstract}
KEYWORD: Water saving; Coal-Fired Power Generation; Lignite; Air-Cooled Condenser ABSTRACT: As fresh water resources are increasingly scarce, water-saving technologies are quite important for power plant in water leaking area. Conventional techniques for saving water in power plant include air-cooled condensers (ACCs) of power generating units, air-cooling of auxiliary cooling water, dry ash removal and desulphurization of activated coke, etc. Conventional water-save technologies will cost much more than non-water-saving technologies. A new water-saving technology named Getting Water from Lignite (GWFL) is proposed in this article. This technology is applied to coal with more than $30 \%$ moisture content, such as lignite. GWFL technology not only recycles water from coal, but also save the heat from the steam out of boiler. It is the most appropriate technology for high moisture coal fired power generation. Other categories of water-saving technologies shall be chosen based on the drought rate and construction budget.
\end{abstract}

\section{INTRODUCTION}

Although, renewable energy has gained rapid development in recent years, substantial reserves and demands mean that coal is and will continue to be the most major energy source in East Asia, particularly in China. By the end of 2010, installed capacity of power generation in china has been reached to $966 \mathrm{GW}$, more than $70 \%$ of which are fossil-fueled power generation. Common coal fired power plant cost large amounts of water. In 2010, water consumption for power generation is $2.5 \mathrm{~kg} /$ kWh.

Uses of water include agricultural, industrial, household, recreational and environmental activities. The majority of human uses require fresh water. 97 percent of the water on the Earth is salt water and only three percent is fresh water; slightly over two thirds of this is frozen in glaciers and polar ice caps. Up to now, many people still live in extremely arid area. Many inland areas are arid but rich in fossil fuel. It is one of the biggest bottlenecks for the development of power station near coal mines. In the arid areas due to its significant water shortage advantage, many water-saving technologies have been developed, such as air-cooled condensers (ACCs) of power generating units, aircooling of auxiliary cooling water, dry ash removal, desulphurization of activated coke, etc.

Brown coal and lignite are characterized by a relatively low heating value, mainly because of the high moisture content, which can vary between 20 and $70 \%$. Therefore, lignite needs to be dried before being ignited to ensure a good ignition and burnout behavior in pulverized coal-fired units. The drying is combined with the grinding process in special milling equipment, the beater wheel mill. But, the drying process cost extra energy and reduce the efficiency of lignite-fired power generation units. A high efficient lignite-fired power generation technology has been developed recently, which based on open pulverizing system with flue gas drying beater wheel mill and recovery of heat and water from pulverizing exhaust.

For water-saving, power plant construction investment and operating cost, different technology has different characteristics. In the current paper, the above water-saving technologies are characterized from technical and economic aspect.

\section{WATER CONSUMPTION IN COAL-FIRED POWER PLANT}

The principal production system in thermal power plants includes steam water system, combustion system and electrical system. The steam system consists of boiler, steam turbine, condenser and feed water pump, etc. In condenser, which is a large surface-type heat exchanger, the steam is condensed, by transferring its latent heat to circulating water taken from cooling medium. If the power plant is settled inland, the cooling medium would be from nearby river or lake, which is also used for agricultural, industrial, household, recreational and environmental activities. In cooling tower, 
some of the circulating water evaporates into air and getting lost, and that is the most major part of total water loses for a common coal fired power plant with wet flue gas desulfurization (FGD). Water consumption in Chinese thermal power plant is shown in Table 1.

Table 1. Water consumption in Chinese thermal power plant

\begin{tabular}{cccc}
\hline Year & 2000 & 2005 & 2010 \\
\hline $\begin{array}{c}\text { Water consumption, } \\
\mathrm{m}^{3} /(\mathrm{s} \cdot \mathrm{GW})\end{array}$ & 1.147 & 0.86 & 0.68 \\
\hline
\end{tabular}

In order to control water consuming of coal fired power plant, some provisions of regulations and standards are proposed, as shown in Table 2 。

Table 2. Relevant standards of water consumption for large capacity $\quad(\geq 300 \mathrm{MW})$ power plant design, $\mathrm{m} 3 /(\mathrm{s} \cdot \mathrm{GW})$

\begin{tabular}{cccc}
\hline $\begin{array}{c}\text { Water supply } \\
\text { system }\end{array}$ & $\begin{array}{c}\text { Guide for wa- } \\
\text { ter saving of } \\
\text { thermal power } \\
\text { plant }\end{array}$ & $\begin{array}{c}\text { Norm of } \\
\text { water in- } \\
\text { take }\end{array}$ & $\begin{array}{c}\text { Code for de- } \\
\text { sign of fossil } \\
\text { fired power } \\
\text { plant }\end{array}$ \\
\hline $\begin{array}{c}\text { Fresh water } \\
\text { cooling }\end{array}$ & $0.6 \sim 0.8$ & $\leq 0.8$ & $\leq 0.7$ \\
$\begin{array}{c}\text { Sea water } \\
\text { cooling }\end{array}$ & $0.06 \sim 0.12$ & $\leq 0.12$ & $\leq 0.1$ \\
Air cooling & $0.13 \sim 0.2$ & - & $\leq 0.06 \sim 0.12$ \\
\hline
\end{tabular}

\section{CONVENTIONAL WATER-SAVING TECHNOLOGIES}

\section{Air-cooled condenser}

In the past decades, direct air-cooled condensers (ACCs) of power generating units gained considerable development in the arid areas due to its significant water-saving advantage (Zhao, 2002). The major benefits of dry cooling are elimination of water usage from the condensing power cycle and flexibility in power plant site selection. The most popular style of Air Cooled Condenser is the modularized A-Frame design used on power plants, as shown in Figure 1. The water saving effect of air-cooled condenser system is remarkable, as shown in Figure 2.

In china, the total investment of a $2 \times 600 \mathrm{MW}$ coal fired power plant with secondary circulation wet cooling system is approximately 38.8 million dollars but that would be more than 75 million for direct air-cooled units. Furthermore, Standard coal cost for air-cooled units are $5 \mathrm{~g} / \mathrm{kWh}$ higher than the same capacity units of wet cooling. 


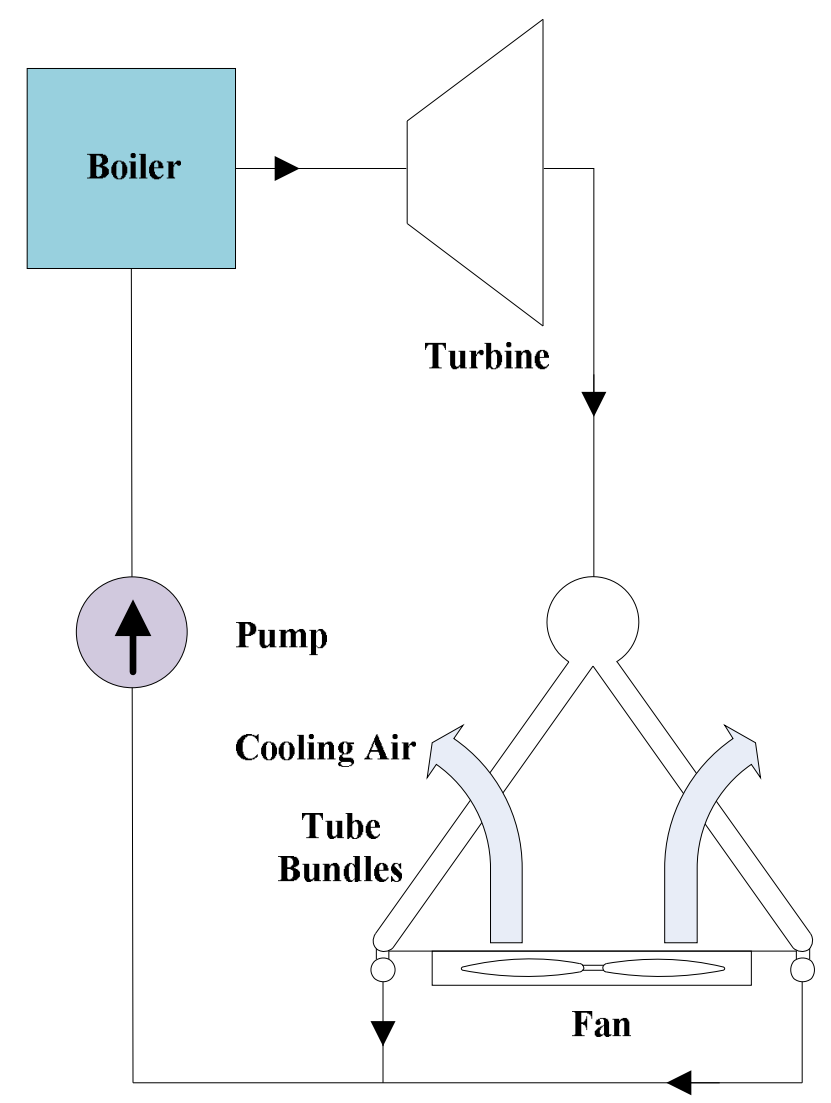

Figure 1 Architecture of the procedures for smart grid project

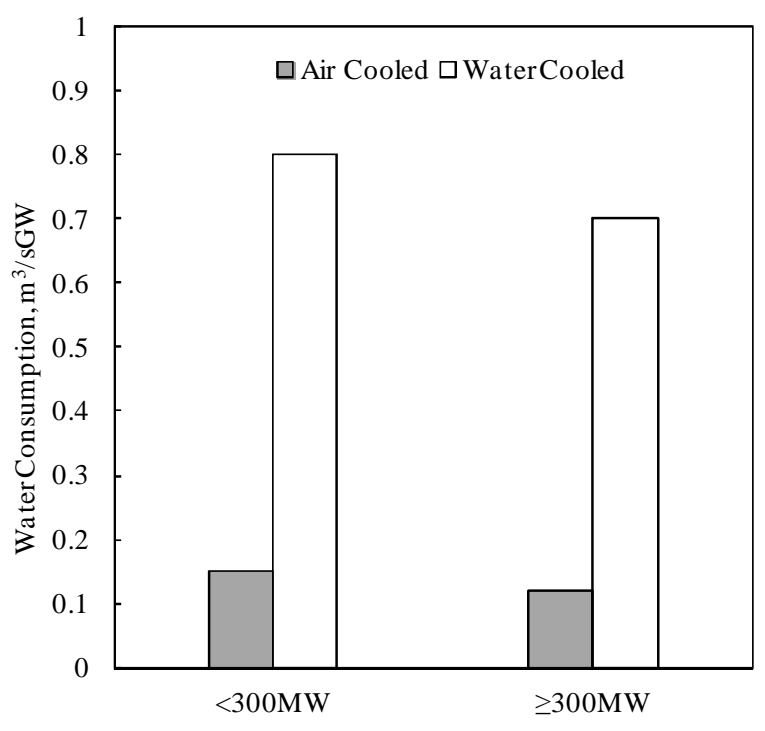

Figure 2 Water cost for coal-fired power generation

\section{Air-cooling of auxiliary cooling water}

Auxiliary cooling water is the cooling water for turbine, generator, pumps, fans, mills, etc. Aircooling of auxiliary cooling water can reduce the water cost for $0.02 \mathrm{~m}^{3} / \mathrm{s}$. GW. The total investment of air-cooling system of auxiliary cooling water for a $2 \times 600 \mathrm{MW}$ coal fired power generation system is approximately 2.9 million dollars, 3-4 time of wet cooling system. 


\section{Dry ash removal}

Dry ash removal use air cooling down and transport the bottom ash of boiler and does not consume any water. The cooling air goes into furnace after heated by hot ash (Chen et al. 2004). Therefore, the air ash removal system increases the boiler efficiency.

For a $2 \times 600 \mathrm{MW}$ coal fired power generation system with air ash removal system, the water cost is decrease $36.0 \mathrm{~m}^{3} / \mathrm{h}$, approximately $0.01 \mathrm{~m}^{3} / \mathrm{s} . \mathrm{GW}$. But, the investment of air ash removal system can be increase 0.75 million dollars.

\section{Activated coke FGD}

Worldwide interest in carbon-based flue gas desulfurization (FGD) technology is growing (Anthony et al, 1996). Such processes have been proved successful at removing up to $95 \%$ of $\mathrm{SO}_{2}$ and $>80 \%$ of $\mathrm{NO}_{\mathrm{x}}$ from combustion flue gas.

An activated carbon FGD process, typically placed after the precipitator and just before the stack, can be used alone or in conjunction with other FGD methods to remove $\mathrm{SO}_{2}$ and $\mathrm{NO}_{\mathrm{x}}$ from flue gas,

Activated carbon FGD belongs to dry recycling desulphurization process (Yin et al, 2011). Activated carbon made from coal is the desulfurization agent. The recycling desulphurization process rely on the adsorption-desorption of $\mathrm{SO}_{2}$, as shown in Figure 3.

During the desulphurization process, there is no water cost. The by-productions of desulphurization include $\mathrm{SO}_{2}$, sulfuric acid, fertilizer, etc.

This technology has been used in Europe and Japan for cleanup of the flue gas from both coal combustion and waste incineration. Presently, no Chinese utility employs a carbon-based process to clean flue gas.

For a $2 \times 600 \mathrm{MW}$ coal fired power generation system with carbon-based FGD technology, water cost can decrease about $0.04 \mathrm{~m}^{3} / \mathrm{s}$. GW, and $80 \times 10^{4} \mathrm{~m}^{3} \sim 100 \times 10^{4} \mathrm{~m}^{3}$ will be saved for a year. The investment of activated coke FGD system for $2 \times 600 \mathrm{MW}$ units is about $3-4$ time of Ca-based FGD system.

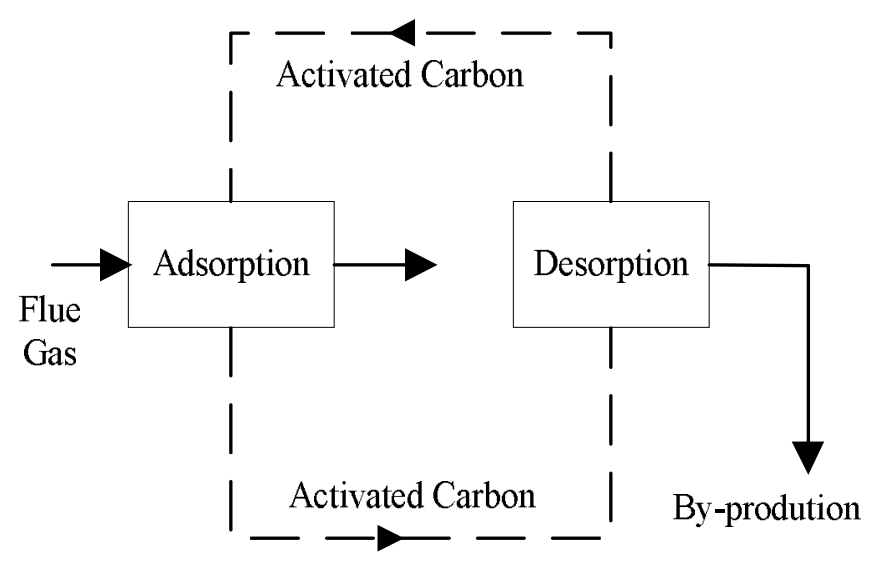

Figure 3. Activated coke FGD system schematic diagram

\section{GETTING WATER FROM LIGNITE COAL}

Brown coal and lignite typically are medium-and high-moisture content, which can vary between 20 and $70 \%$ that are used either in circulating fluidized bed or in modern, highly efficient, pulverized coal-fired boilers with tangentially systems. $13 \%$ of all the coal reserves in China are Lignite, but China has heavy disparity compared with German and other advanced lignite firing countries (Zheng et al. 2013). 


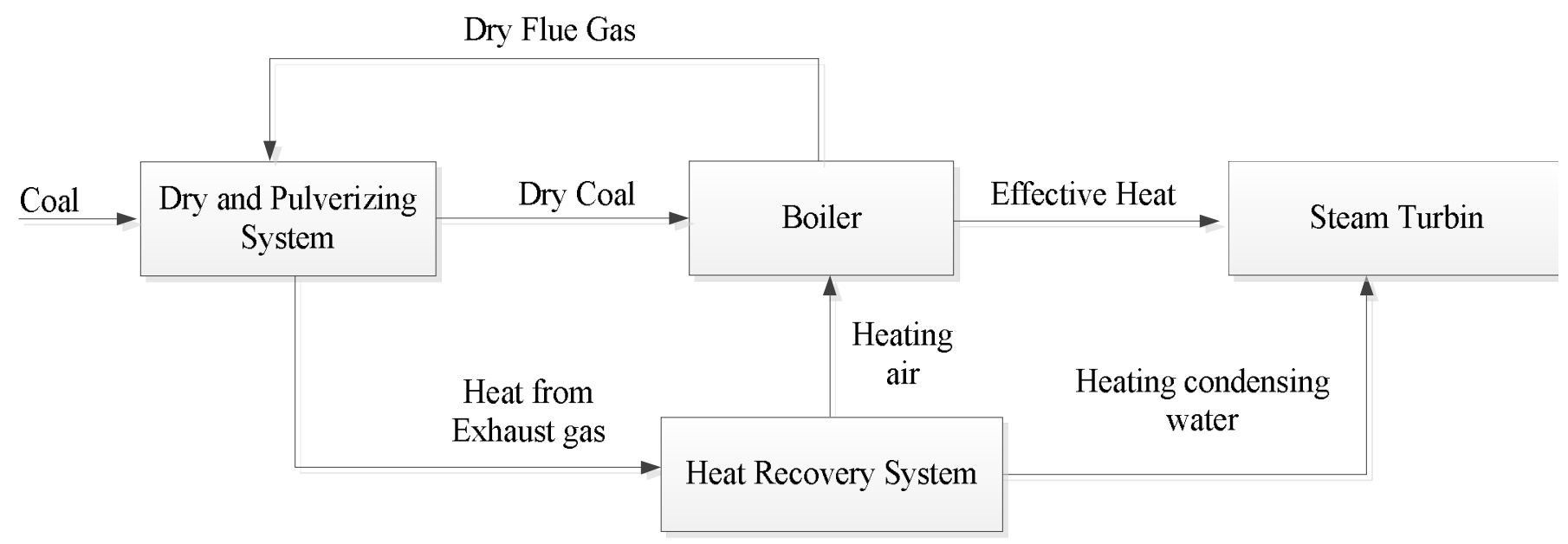

Figure 4. Energy transfer and conversion of GWFL high-efficiency power generation system.

A high-efficiency power generation technology have been developed that is efficient lignite-fired power generation technology based on open pulverizing systems with flue gas drying beater wheel mill and recovery of heat and water from pulverizing exhaust (Ma et al, 2013), for short is Getting Water from Lignite (GWFL).

The working principle of GWFL is: mixed the high-temperature furnace gas extracted from the upper part of the boiler furnace and the low-temperature flue gas taken from the rear of the boiler together as a desiccant and then deliver this desiccant though the membrane-cooled hightemperature flue gas pipeline to the downstream Drying tube to mixed with raw coal in order to turn the most moisture of the raw coal quickly into steam, then entering into the fan mill for grinding and turn the part of the remaining moisture of the pulverized coal into steam, complete the drying of water into steam in order to complete drying. After separated by a pulverized coal collector, the pulverized coal fall into the pulverized coal bunker and delivered to the furnace by the pulverized coal feeder for combustion. The steam exhausted from the pulverized coal collector entering into the 'heat water recovery device', after cooling, it becomes condensate. This condensate was carefully analyzed and found it is equivalent to the distilled condensate which can be recycled into the water treatment system. Figure 4 shows the sketch of GWFL with air cooled system.

GWFL technology couples coal-fired power generation technology with lignite drying and heat and water recovery technology, achieves high-efficiency, energy and water saving power generation. As shown in table 3, applying the new technologies on air cooling supercritical or ultrasupercritical unit can achieve 'zero water makeup'; that provide more choices of the power plant location. The new power plant can be located far from river, reservoir and city; that will optimize power plant distribution and the power grid structure, save the city land resources, promote the enterprise image and local harmonious and healthy development.

Table 3. Water saving for different technology

\begin{tabular}{cc}
\hline Water-save technology & $\begin{array}{c}\text { Water cost, } \\
\mathrm{m}^{3} / \mathrm{s} . \mathrm{GW}\end{array}$ \\
\hline Turbine air-cooled & 0.12 \\
Add dry ash removal & 0.10 \\
Add auxiliary equipment air-cooled & 0.08 \\
Add activated coked desulphurization & 0.04 \\
GWFL & Under 0.02 \\
\hline
\end{tabular}




\section{CONCLUSIONS}

As fresh water is becoming more and more scarce resources, water-saving technologies are quite important for power generation in water leaking area.

Conventional technologies for saving water in power plant include ACC of power generating units, air-cooling of auxiliary cooling water, dry ash removal and carbon-based FGD, etc. They will increase the investment and operation cost, and decrease the system efficiency.

ACC technology is the first choice for power generation water saving. It is mature technology and has significant effect for water saving. For extremely arid area, air-cooling of auxiliary cooling water, dry ash removal and carbon-based FGD can be used, according to the investment budget.

For lignite-fired units, GWFL technology is the best choice. GWFL technology couples coal-fired power generation technology with lignite drying and heat and water recovery technology, achieves high-efficiency, energy and water saving power generation. Applying the new technologies on air cooling supercritical or ultra-supercritical unit can achieve 'zero water makeup'; achieves highefficiency, energy and water recycle.

\section{REFERENCES}

[1] Anthony A. Lizzie, Joseph A. DeBarr. 1996. Effect of surface area and chemisorbed oxygen on the SO2 adsorption capacity of activated char. Fuel, Vol. 75, No. 13, pp. 1515-1522,

[2] Chen Y, Liu Q. 2004. Dry slag removal system applied to homemade 200MW unit, Jilin Electric Power, No.6, 41-44.

[3] Ma Y, Guo X, Xiao F, et al., 2013. Efficient Lignite fired Power Generation Technology Based on Open Pulverizing Systems With Flue Gas Drying Fan Mill and Recovery of Heat and Water From Pulverizing Exhaust, Proceedings of the CSEE, Vol.33 No.5, 13-22.

[4] Yin Z, Li Z, Shi X. 2011. Application and technical economic analysis of activated coke desulphurization, China resources comprehensive utilization, Vol. 29, No.28, 31-34.

[5] Zheng L, Sun F. 2013. Application of Lignite Pre-drying Technology, Jilin Electric Power, Vol. 41 No.2 19-21.

[6] Zhao L. 2002. Research on economy of air cooling unit, Degree thesis. North China Electric Power University, Beijing. 